\title{
Object handling workshops in an online teaching environment
}

\section{Jessica Clarke}

University College London

Keywords: object handling; group work; interactive seminars; Covid-19.

\section{The challenge}

The move to an online teaching environment in autumn 2020, created a significant challenge in the delivery of a specific first-year undergraduate history module taught at my university. The module was designed to introduce students to the key concepts of space, place and material culture. In 'normal' academic years, the students were required to visit physical sites and cultural organisations around London (including museums, archives, libraries) and to participate in classes that were based around group work and hands-on activities.

One of the most challenging seminars to adapt was the object handling workshop in week three of the module. Object-based learning is multisensory engagement with material culture, be it artefacts, manuscripts, or archival items, and, as such, is intended to be an interactive learning experience for the students (Chatterjee et al., 2015; Chatterjee and Kador, 2021). In previous years, the aim of the workshop was to have the students (15 in total) engage tactilely with material culture, which would encourage them to think critically about objects as historical sources (Romanek and Lynch, 2008; Hannan et al., 2013). During the seminar, the students would have been put into groups and given a selection of objects to handle and discuss. They would then have been asked to identify each object based solely on their observation of its physical characteristics.

My aim with the online version of this session was to adapt the original workshop so that the students still encountered material culture from a practical perspective. As has been made clear by recent studies into the effectiveness of online teaching (Gonzalez et al., 2020; Hodges et al., 2020), when online lessons are carefully planned and enthusiastically 
delivered, they can be just as effective as in-person teaching. For this session, I was keen to maintain the active learning aspect of the original workshop so that the students would work together and develop their own ideas prior to the identification of each object. So, whilst students would not get a tactile experience, they would still have exposure to artefacts in a way that would require speculation and stimulate discussion.

\section{The response}

After some discussion with colleagues, I decided to create a handout with images of six different objects that were difficult to identify without additional information. To ensure that everyone had access to the images, I made them digitally available 15 minutes before the lesson. I did not, however, circulate them earlier than this, as I wanted to ensure that the students came to the images without previously having studied them. In selecting the images, I aimed to choose a variety of objects which all had physical characteristics that would stimulate debate.

The six objects selected were as follows: an $18^{\text {th }}$ century token from the Vauxhall pleasure gardens, with a barely visible inscription; a piece of whale bone which had signs of being used as part of ship repairs, found near Greenland dock in London; a bone stylus also found in the London docklands; an ornamental mouse from the top of a Roman lamp; the top of a medieval pottery drinking flask; and a set of Georgian wig curlers. The objects were thus not united by any factor other than their visual interest and the challenge of determining their origin and function.

Using Zoom breakout rooms, I divided the class into three groups and gave them four minutes per image (30 minutes overall) to discuss the possible identification of each object. Using the 'send to all' function of the breakout rooms, I told the whole class to change image every four minutes.

During the activity, I moved between breakout rooms, encouraging the students to identify visual clues that might suggest each object's date, use and material. Then, to conclude the session, we had a class discussion during which I asked the groups to reveal their 
identification of each object and give their reasoning. I then shared what each object was, using PowerPoint slides with additional images that contextualised each object.

This feedback portion of the session illustrated the variety of interpretations that could be offered for a single object and encouraged further discussion about the reliability of material culture as a historical source. This brought the discussion back to the compulsory reading that the students had been set (Riello, 2009), which encouraged them to think about the historical narratives in which material culture can be embedded. These discussions were lively, with the majority of the class participating, which indicated that the students were both enjoying the session and engaging with the intended learning outcomes.

\section{Recommendations}

One of the benefits of teaching this workshop online, rather than in person, was being able to use Zoom breakout rooms to divide up the class. This allowed each group to discuss without overhearing the other, and, as a result, when the class came back together, the students benefited from hearing a diverse range of opinions and approaches. My first recommendation for the adaptation of object handling workshops, therefore, would be to make full use of the new online teaching tools. By taking advantage of the tools offered by Zoom, it was possible to create a session that was highly engaging, despite it being very different from the in-person equivalent.

Indeed, the success of this adapted workshop was clearly demonstrated by the enthusiasm and participation of the students (on the importance of first-year seminar participation during the pandemic, see Hauck et al., 2020). From my observation of the individual group discussions, it was clear that the students appreciated having a session that approached historical sources from a new and refreshing angle.

Moreover, a second recommendation would be to allow the improvements made to online seminars to filter back through to in-person teaching in the future. Something that emerged from this workshop, for example, was a discussion of the context in which some of the objects were found. This was prompted by several of the images showing the object in its 
original findspot rather than its display context. This is a conversation that was not always possible during in-person sessions, where the objects were seldom provided with any contextual data. When we return to in-person teaching, I aim to ensure that this discussion of context is regularly incorporated into the seminar.

Although they were not able to handle the objects directly, the session still encouraged students to treat material culture critically. No doubt colleagues in any discipline which deals with material culture can also experiment with alternative ways of teaching object handling activities, as what is lost in terms of actual touch can be compensated for and enhanced with new methods of approach and delivery.

\section{References}

Chatterjee, H.J., Hannan, L. and Thomson, L. (2015) 'An introduction to object-based learning and multisensory engagement', in Chatterjee, H. J. and Hannan, L., (eds.) Engaging the senses. object-based learning in higher education. New York: Routledge, pp.1-18.

Chatterjee, H.J. and Kador, T. (eds.) (2021) Object-based learning and object-based wellbeing. exploring material connections. New York: Routledge.

Gonzalez, T., De la Rubia, M.A., Hincz, K.P., Comas-Lopez, M., Subiratas, L., Fort, S. and Sacha, G.M. (2020) 'Influence of COVID-19 confinement on students' performance in higher education', PLOS ONE, 15(1), pp. 1-23. Available at: https://doi.org/10.1371/journal.pone.0239490 (Accessed: 3 September 2021).

Hannan, L., Duhs, R. and Chatterjee, H. (2013) 'Object-based learning: a powerful pedagogy for higher education', in Boddington, A., Boys, J. and Speight, C. (eds.) Museums and higher education working together. challenges and opportunities. Farnham: Ashgate Publishing Company, pp. 159-168.

Hauck, A.A., Ward, C., Persutte-Manning, S.L. and Vaughan, A.L. (2020) 'Assessing firstyear seminar performance with college engagement, academic self-efficacy, and 
student achievement,' Journal of Higher Education Theory and Practice, 20(4), pp.88-101. Available at: https://doi.org/10.33423/jhetp.v20i4.2988 (Accessed: 3 September 2021).

Hodges, C., Moore, S., Lockee, B., Trust, T. and Bond, A. (2020) 'The difference between emergency remote teaching and online learning', EDUCAUSE, pp. 1-15. Available at: https://er.educause.edu/articles/2020/3/the-difference-between-emergencyremote-teaching-and-online-learning (Accessed: 3 September 2021).

Riello, G. (2009) 'Things that shape history. material culture and historical narratives', in Harvey, K. (ed.) History and material culture. a student's guide to approaching alternative sources. London: Routledge, pp. 27-50.

Romanek, D. and Lynch, B. (2008) 'Touch and the value of object handling: final conclusions for a new sensory museology', in Chatterjee, H.J. (ed.) Touch in museums: policy and practice in object handling. Oxford and New York: Berg. pp. 275-286.

\section{Author details}

Jessica Clarke is a Senior Postgraduate Teaching Assistant in the History Department at University College London and an Associate Fellow of the Higher Education Academy. 